\title{
Effect of Water-impregnation on Steam Explosion of Pinus densiflora ${ }^{1}$
}

\author{
Ji Young Jung ${ }^{2} \cdot \mathrm{Si}$ Young $\mathrm{Ha}^{2} \cdot$ Jae-Kyung Yang ${ }^{2, \dagger}$
}

\begin{abstract}
This study addresses the biorefinery feedstock from Pinus densiflora. This raw material is a major tree species in the Republic of Korea; it is renewable, has cost-effective, and is readily available. In this study, steam explosion of $P$. densiflora was performed in a reactor at $225{ }^{\circ} \mathrm{C}$ and with 1 to 13 min reaction times with or without previous water impregnation. The combined severity factor $(R o)$, which is an expression relating the reaction temperature and reaction time used in the steam explosion treatment, ranged from 3.68 to 4.79. The influence of both impregnation and steam explosion conditions were investigated by examining color variations, chemical composition, and mass balance on the pretreated solids. The results showed that steam-exploded $P$. densiflora that was not impregnated with water exhibited significantly darker color (chroma 28.8-41.4) than water-impregnated and steam-exploded $P$. densiflora (chroma 18.8-37.3). The increased $\alpha$-cellulose and lignin contents were detected as the severity factor increased. Furthermore, the $\alpha$-cellulose and lignin contents in the non-impregnated/steam-exploded $P$. densiflora were higher than those in the water-impregnated/steam-exploded $P$. densiflora. However, the decreased holocellulose content was detected as the severity factor increased. In mass balance, the holocellulose yield from water-impregnated/steam-exploded $P$. densiflora was higher than that from the non-impregnated $P$. densiflora.
\end{abstract}

Keywords: Pinus densiflora, softwood, impregnation, steam explosion, biorefinery

\section{INTRODUCTION}

Lignocellulosic biomass is an inexpensive, renewable, and abundant source of biorefinery fuel. Biorefinery fuel can be produced from various lignocellulosic biomasses such as wood, agricultural, or forest residues (Maurya et al., 2015). Full feedstock recovery requires the optimum utilization of all lignocellulosic components as marketable products and should be one of the major goals of optimizing a biomass-to-ethanol conversion process. Ideally, bioconversion in the wood- to-ethanol conversion process should convert all wood carbohydrates in the feedstock to ethanol. It is generally recognized that the recovery of all components will be compromised because of the complex nature of the lignocellulosic substrates and the technical difficulties associated with their separation and conversion to marketable products (Boussaid et al., 1999). Although significant advances have been made in the bioconversion of hardwood and agricultural residues, progress on softwood feedstocks has proven more difficult. Biomass from softwood, e.g., pine and spruce, is a very abundant

\footnotetext{
${ }^{1}$ Date Received December 18, 2018, Date Accepted February 21, 2019

2 Division of Environmental Forest Science and Institute of Agriculture \& Life Science, Gyeongsang National University, Jinju 52828, Republic of Korea

† Corresponding author: Jae-Kyung Yang (e-mail: jkyang@gnu.ac.kr, ORCID: 0000-0003-0423-6398)
} 
feedstock and is a viable alternative to more typical materials such as grass and straw (Kim et al., 2016). However, implementation of softwood biomass in ethanol production is very sensitive because of the high lignin content and the difficulties associated with the steam explosion pretreatment, which is required for disrupting the lignin carbohydrate matrix. To date, no viable process for softwood-to-ethanol conversion has been established.

Steam explosion is widely used in a variety of lignocellulosic biomasses for fractionation of the main components (cellulose, hemicellulose, and lignin) (Jung et al., 2017a). To date, steam explosion is known to be one of the most desirable pretreatment methods for fractionation of biorefinery fuel because of its high yield and low capital and production costs (Avellar and Glasser, 1998). The method is effective over a wide variety of plant biomasses including hardwoods (Excoffier et al., 1991; Ramos et al., 1992; Jung et al., 2013; Jung et al., 2017a), softwoods (Schwald et al., 1989, Jung et al., 2018), and agricultural residues such as Miscanthus sinensis (Jung and Yang, 2016), sugar cane bagasse (Kling et al., 1987), wheat straw (Tenrud et al., 1989), barley husk (Jung et al., 2017b) and corn stover (Ropars et al., 1992). If softwoods are to be used, an acid catalyst must be combined with steam (Boussaid et al., 1999; Clark and Mackie, 1987). Several organic acids, particularly $\mathrm{H}_{2} \mathrm{SO}_{4}$, were proposed as effective catalysts (Lee and Jeffries, 2011; Galbe and Zacchi, 2002). Moreover, $\mathrm{SO}_{2}$ was shown to have several advantages as an acid catalyst, such as its rapid penetration in and uniform distribution throughout wood chips (Mamers and Menz, 1984; Wayman et al., 1984). Therefore, steam explosion is an interesting method for use in biorefinery industry, but it should be assisted by impregnation of the raw material with an acid species, such as sulfuric acid or sulfur dioxide (Galbe and Zacchi, 2007), if it is to be effective on softwood. However, the use of different impregnating agents can affect the reactivity of the pretreated biomass, the formation of microbial inhibitors, and toxicity. Furthermore, less attention was paid to the initial size and moisture content of the lignocellulosic feedstock. These two parameters are known to influence the effectiveness of steam explosion (Brownell et al., 1986; Ballesteros et al., 2000; Monavari et al., 2009; Ewanick and Bura, 2011).

Pinus densiflora (Korean red pine) is one of the major plantation tree species in the Republic of Korea because of the high value wood products and nuts (Son et al., 2007), covering about $8.6 \%$ of the total forest area in Korea (Korea Forest Service 2008). Aspenwood, douglas fir, spruce, and pine (pinus pinaster, pinus radiata) were used as raw materials in previous studies on steam explosion of softwood, and there are few studies that focus on Pinus densiflora.

The aim of this study was to elucidate the effect of steam explosion in P. densiflora wood chips after impregnation by water rather than chemicals. In particular, the effects of water impregnation (with or without) and steam explosion conditions on the color variations, chemical composition, and mass balance of $P$. densiflora wood chip were focused in this study.

\section{MATERIALS and METHODS}

\subsection{Raw material}

Pinus densiflora was collected from the forest around the city of Hongcheon in Republic of Korea. $P$. densiflora was chipped to a particle size of approximately $2 \times 2 \times 0.5 \mathrm{~cm}^{3}$ for the steam explosion treatment and stored at $20{ }^{\circ} \mathrm{C}$.

\subsection{Impregnation and steam explosion treatment of wood chips}

Impregnation of dried $P$. densiflora was achieved by soaking $100 \mathrm{~g}$ of dry chipped wood in $1 \mathrm{~L}$ of water 
Table 1. Condition of the steam explosion of $P$. densiflora

\begin{tabular}{|c|c|c|c|}
\hline \multirow{2}{*}{ Impregnation } & \multicolumn{3}{|c|}{ Steam explosion condition } \\
\hline & Temperature $\left({ }^{\circ} \mathrm{C}\right)$ & Reaction time (min) & Severity factor $\left(R_{0}\right)^{1)}$ \\
\hline \multirow{4}{*}{ Non-impregnation } & \multirow{4}{*}{225} & 1 & 3.68 \\
\hline & & 3 & 4.16 \\
\hline & & 7 & 4.53 \\
\hline & & 13 & 4.79 \\
\hline \multirow{4}{*}{ Water-impregnation } & \multirow{4}{*}{225} & 1 & 3.68 \\
\hline & & 3 & 4.16 \\
\hline & & 7 & 4.53 \\
\hline & & 13 & 4.79 \\
\hline
\end{tabular}

1) Severity factor $\left(R_{0}\right)=t * \exp (T-100 / 14.75)$

for $16 \mathrm{~h}$. The excess water was filtered off after soaking. Impregnated $P$. densiflora was then steam-exploded in a reactor of the steam explosion apparatus with maximum operating pressure of $30 \mathrm{~kg} / \mathrm{cm}^{2}$.

P. densiflora was steamed at $225{ }^{\circ} \mathrm{C}$ from $1 \sim 13 \mathrm{~min}$ (corresponding to severity factors $(R o)$ of $3.68 \sim 4.79$ ) for water impregnation before a sharp decompression. The severity factor $(R 0)$ was calculated using the following equation (Overend and Chornet, 1987): Severity $\log (R o)=\log \{t \times \exp (T-100 / 14.75)\}$ where $t$ is the residence time in minutes and $T$ is the reaction temperature in ${ }^{\circ} \mathrm{C}$ (Table 1). Non-impregnated, steamexploded $P$. densiflora was used as a control. After the explosion, the material was recovered in a cyclone. The wet material was cooled to about $40{ }^{\circ} \mathrm{C}$ and filtered to recover solids. The solid fraction was analyzed using the procedures described below.

\subsection{Color measurement}

Three grams of a sample was weighed and diluted with water into a slurry. The slurry was filtered through a clean filter paper, and one clean filter paper was placed on the top of the pad while filtering. The top side of the pad was placed in such a way that it faced a clean metal plate. Two dry blotters were also used. The pad was pressed in a sheet at $0.275 \mathrm{MPa}$ for one minute.
The pad was dried at about $65{ }^{\circ} \mathrm{C}$ for $1 \mathrm{~h}$ with an IR lamp. The color measurement was gathered using an Elrepho 2000 brightness tester at $\mathrm{D}_{65}$ (Elrepho, L\&W, Sweden). The CIE color system uses three coordinates $(L, a$, and $b$ ) to define a color space. $L$ axis represents lightness, which varies from 100 (white) to 0 (black); $a$ and $b$ are the chromaticity coordinates, representing red-green and blue-yellow, respectively (Cetera et al., 2019).

\subsection{Chemical composition analysis}

The $\alpha$-cellulose content (TAPPI T-203 OM 88) was calculated by further treating the cellulose fibers with $\mathrm{NaOH}$ after determining holocellulose content. $5 \mathrm{~g}$ of the sample was mixed with $7.5 \% \mathrm{NaOH}$ reagent and stirred at $25{ }^{\circ} \mathrm{C}$ for $1 \mathrm{~h}$. The pulp suspension was filtered at the end of this $1 \mathrm{~h}$ period. The chemical composition was determined using the filtrate. $25 \mathrm{ml}$ of the prepared filtrate and $10 \mathrm{ml}$ of $0.5 \mathrm{~N}$ potassium dichromate were mixed with $50 \mathrm{ml}$ of concentrated sulfuric acid while stirring. $50 \mathrm{ml}$ of water was added to the mixture, followed by 2 drops of ferroin indicator. This was titrated against $0.1 \mathrm{~N}$ ferrous ammonium sulfate solution to a purple color. $12.5 \mathrm{ml}$ of $17.5 \% \mathrm{NaOH}$ and 12.5 $\mathrm{ml}$ of water were used as a blank.

The hydrolysate produced via acid hydrolysis (ASTM 
method E1721-95) was then analyzed for the sugar content. The holocellulose (arabinose, xylose, mannose, galactose, glucose) content in this hydrolysis liquid was then analyzed using gas chromatography (GC) in a YL6100 device (Young Lin Ins. Co., Ltd., City, Korea) after hydrolysis with sulfuric acid and conversion into alditol acetates.

The lignin (NREL/TP-510-42618) and ash (NREL/ TP-510-42622) contents in the samples were determined using the ASTM method E1721-95. Biomass samples ( $0.3 \mathrm{~g}$ ) were hydrolyzed with $72 \%$ sulfuric acid for $2 \mathrm{~h}$ at $30{ }^{\circ} \mathrm{C}$. The hydrolyzed samples were diluted with distilled water to $3 \%$ sulfuric acid concentration and autoclaved at $121{ }^{\circ} \mathrm{C}$ for $1 \mathrm{~h}$. The hydrolysates were filtered through filtering crucibles. The residues were dried overnight at $105{ }^{\circ} \mathrm{C}$ in a laboratory oven and weighed. The residues were then ash in a muffle furnace at $575{ }^{\circ} \mathrm{C}$ for $3 \mathrm{~h}$, cooled in a desiccator, and weighed. The ash and acid insoluble residue contents were calculated on an oven dry basis.

The content of extractives (NREL/TP-510-42619) in the solubilized material was determined after soxhlet extraction with ethanol at the boiling point for $6 \mathrm{~h}$.

The protein content (NREL/TP-510-42625) was estimated using an CHN analyzer (Flash 2000 Series, Thermo Fisher Scientific Inc, USA).

\subsection{Statistical Analysis}

ANOVA was used to determine the impregnation and steam explosion effects from the obtained data. All analytical determinations were performed in duplicate, and the average results are shown here. Statistical analysis was conducted with SAS statistical software, and the ANOVA test results and were compared to the mean from the data using Duncan's test. Duncan's multiple comparison range test was used to determine significant differences $(\mathrm{p}<0.05)$ between the means.

\section{RESULTS and DISCUSSION}

\subsection{Effect of impregnation and steam explosion on color variations of $P$. densiffora}

The $P$. densiflora wood chip were subjected to steam explosion under different conditions, namely nonimpregnation or water impregnation.

Fig. 1 shows a $P$. densiflora sample subjected to steam explosion. Steam explosion condition of $P$. densiflora yielded products with darker color than the raw material. The appearance of the $P$. densiflora samples changed considerably after steam explosion. The color of the wood gradually turned darker as Ro for the treatment increased, as shown in Fig. 1. These darker color products might have formed from Maillard reactions. A Maillard reaction can occur during steam explosion, where degrading reactions are the main contributor to sugar loss and thermal decomposition of lignin to vanillin. Some products of these reactions are very volatile, and a distinctive sweet smell can be observed during steam explosion (Sørensen et al., 2008).

The color of the steam-exploded $P$. densiflora was dark brown when Ro was 4.79 due to the relatively long treatment time regardless of water impregnation.

In this color space, a color is defined by its Cartesian chromatic coordinates. The lightness $L$ varies from 0 (black) to 100 (white). Coordinates $a$ and $b$ define the chromaticity plane; the color varies from green to magenta along the $a$ axis and from blue to yellow along the $b$ axis. This system is often used to quantify the natural color of woods (Mazet, 1988) or to trace color modifications during photochemical ageing of abies (Dirckx et al., 1992) or oak (Mazet et al., 1993).

Steam explosion strongly modifies the color with overall color differences ( $L, a, b$, and whiteness) between untreated and treated samples (Table 2). The value of $a$ increased from 8.6 to 11.1, and whiteness 
Effect of Water-impregnation on Steam Explosion of Pinus densiflora

\begin{tabular}{|c|c|c|}
\hline \multirow{2}{*}{ Steam explosion condition } & \multicolumn{2}{|c|}{ Impregnation } \\
\cline { 2 - 3 } Severity factor $\left(R_{0}\right) 3.68$ & Non-impregnation & Water-impregnation \\
\hline Severity factor $\left(R_{0}\right) 4.16$ & & \\
\hline Severity factor $\left(R_{0}\right) 4.53$ & & \\
\hline
\end{tabular}

Fig. 1. Images of the $P$. densiflora before and after non-impregnation or water-impregnation and steam explosion condition.

Table 2. Effect of impregnation and steam explosion condition on color values of P. densiflora

\begin{tabular}{|c|c|c|c|c|}
\hline \multirow{2}{*}{ Severity factor $\left(R_{0}\right)$} & \multicolumn{4}{|c|}{ Color values } \\
\hline & $L^{1)}$ & $a^{2)}$ & $b^{3)}$ & whiteness \\
\hline Untreated & $77.7 \pm 0.9 a^{4)}$ & $6.1 \pm 0.5 \mathrm{f}$ & $26.8 \pm 0.6 \mathrm{a}$ & - \\
\hline \multicolumn{5}{|c|}{ Non-impregnation } \\
\hline 3.68 & $51.1 \pm 0.5 \mathrm{~d}$ & $8.6 \pm 0.1$ de & $20.0 \pm 0.1$ ef & 28.8 e \\
\hline 4.16 & $47.5 \pm 0.3 \mathrm{e}$ & $10.1 \pm 0.2 \mathrm{c}$ & $22.9 \pm 0.2 b$ & $32.0 \mathrm{~d}$ \\
\hline 4.53 & $44.7 \pm 0.3 \mathrm{f}$ & $10.6 \pm 0.1 \mathrm{~b}$ & $21.7 \pm 0.3 \mathrm{c}$ & $35.0 \mathrm{c}$ \\
\hline 4.79 & $38.3 \pm 0.6 \mathrm{~h}$ & $11.1 \pm 0.2 \mathrm{a}$ & $20.8 \pm 0.5 \mathrm{~d}$ & $41.4 \mathrm{a}$ \\
\hline \multicolumn{5}{|c|}{ Water-impregnation } \\
\hline 3.68 & $61.6 \pm 0.7 b$ & $6.5 \pm 0.2 \mathrm{f}$ & $19.5 \pm 0.3 \mathrm{f}$ & $18.8 \mathrm{~h}$ \\
\hline 4.16 & $53.7 \pm 0.6$ c & $8.5 \pm 0.0$ e & $21.8 \pm 0.4 \mathrm{c}$ & $25.9 \mathrm{~g}$ \\
\hline 4.53 & $51.4 \pm 0.2 \mathrm{~d}$ & $8.9 \pm 0.1 \mathrm{~d}$ & $21.6 \pm 0.3 \mathrm{c}$ & $28.2 \mathrm{f}$ \\
\hline 4.79 & $42.4 \pm 0.1 \mathrm{~g}$ & $9.9 \pm 0.1 \mathrm{c}$ & $20.4 \pm 0.3 \mathrm{de}$ & $37.3 \mathrm{~b}$ \\
\hline
\end{tabular}

\footnotetext{
1) $L$ : lightness

2) $a$ : green-red coordinate

3) $b$ : blue-yellow coordinate

4) In each column, values with different letters indicate statistically significant differences $(\mathrm{p}<0.05)$ by Duncan's test
} 
increased from 28.8 to 41.4 as $R$ o increased from 3.68 to 4.79 without impregnation. Also, the value of $a$ increased from 6.5 to 9.9 and whiteness increased from 18.8 to 37.3 as Ro increased 3.68 to 4.79 after water impregnation. The value of $L$ decreased from 51.1 to 38.3 as Ro increased 3.68 to 4.79 without impregnation. $L$ also decreased from 61.6 to 42.4 as Ro increased from 3.68 to 4.79 after water impregnation.

Steam-exploded $P$. densiflora without water impregnation exhibited significantly darker color (lower $L$, higher $a$, and higher whiteness values) than waterimpregnated and steam- exploded P. densiflora.

\subsection{Effect of impregnation and steam explosion on chemical composition of $P$. densiflora}

The main components in the steam-exploded $P$. densiflora with/without impregnation and at various steam explosion conditions are shown in Figs. 2 to 4. The chemical composition of $P$. densiflora was obviously different depending on impregnation and steam explosion conditions.

The $\alpha$-cellulose and holocellulose contents in the untreated, non-impregnated/steam- exploded and waterimpregnated/steam-exploded $P$. densiflora are shown

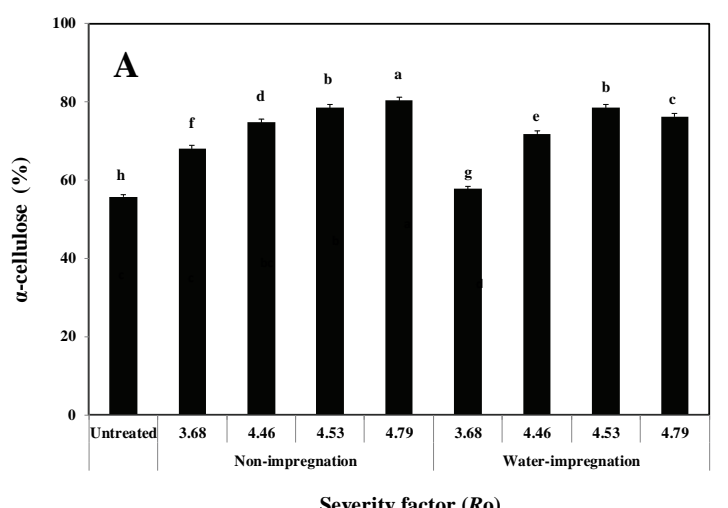

in Fig. 2A.

The $\alpha$-cellulose content in steam-exploded $P$. densiflora ranged between $68.1 \%$ and $80.1 \%$ when $R$ o ranged from 3.68 to 4.79 . Also, the $\alpha$-cellulose content in water-impregnated/steam- exploded $P$. densiflora ranged between $57.8 \%$ and $76.2 \%$ when $R$ o ranged from 3.68 to 4.79 . An increase in the $\alpha$-cellulose content was detected as $R o$ increased. The $\alpha$-cellulose content in the non-impregnated/steam-exploded $P$. densiflora was higher than that in the water-impregnated/steamexploded $P$. densiflora.

The decreased holocellulose content was detected as the severity factor increased (Fig. 2B). Holocellulose reduction occurs due to hemicellulose (arabinose, xylose, mannose, and galactose) reduction. These results show that more hemicellulose degraded with increased temperature and residence time (Ro), confirming that hemicellulose became solubilized as oligomers (Liu and Wyman, 2003). However, the increased glucose content was detected as Ro increased. These results are consistent with the increased cellulose content as $R 0$ increased. Various studies show that thermochemical treatments tend to increase the crystallinity index of the cellulose fraction, resulting in decreased accessibility of the wood material. This increased crystallinity

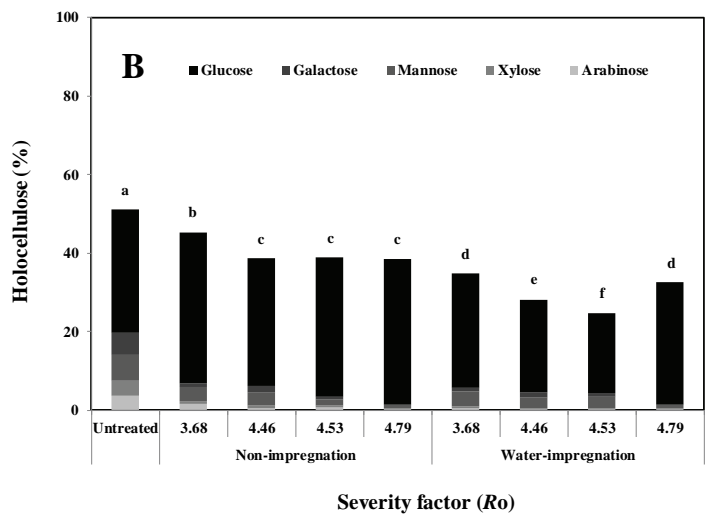

Fig. 2. Effects of impregnation and steam explosion condition on $\alpha$-cellulose (A) and holocellulose (B) content of $P$. densiflora. Holocellulose: sum of glucose, galactose, mannose, xylose and arabinose. 


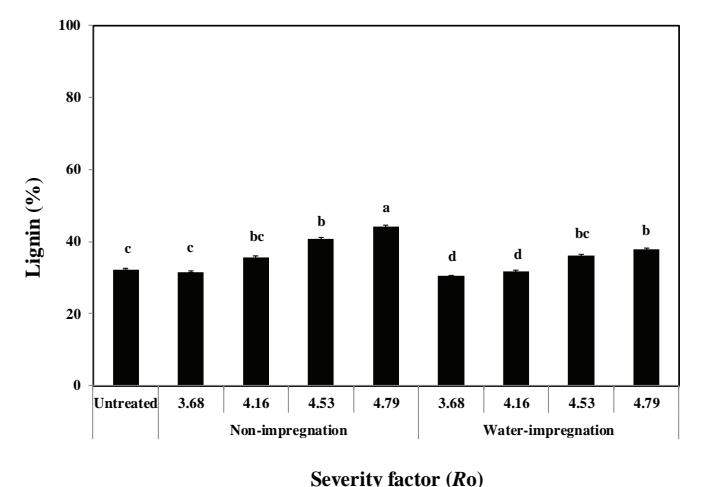

Fig. 3. Effects of impregnation and steam explosion condition on lignin content of $P$. densiflora.

is attributed to recrystallization of the amorphous cellulose induced by rearrangement of the cellulose chains at high temperature and pressure (Jacquet et al., 2012).

The lignin content in the steam-exploded $P$. densiflora increased when $R$ o ranged from 3.68 to 4.79 (Fig. 3). The lignin content in the non-impregnated/ steam-exploded $P$. densiflora was higher than that in the water-impregnated/steam-exploded $P$. densiflora. Lignin softens during steam explosion of wood, becomes released from the cell wall, and distributes evenly throughout the wood (Oberberger and Thek, 2010).

The minor components (extractive, ash, and protein) in the steam-exploded $P$. densiflora for different impregnation and steam explosion conditions are shown in Fig. 4.

The steam explosion treatment resulted in a significant increase in the extractive content for ethanol solvents (Fig. 4A). The water-impregnated/steamexploded $P$. densiflora extracted with ethanol exhibited extractive contents of $13.0 \%$ and $25.4 \%$, respectively. The increase in extracts following steam explosion might be due to degradation of high molecular weight components and conversion from insoluble to soluble components (Shoulaifar et al., 2014).

The non-impregnated and steam-exploded P. densiflora
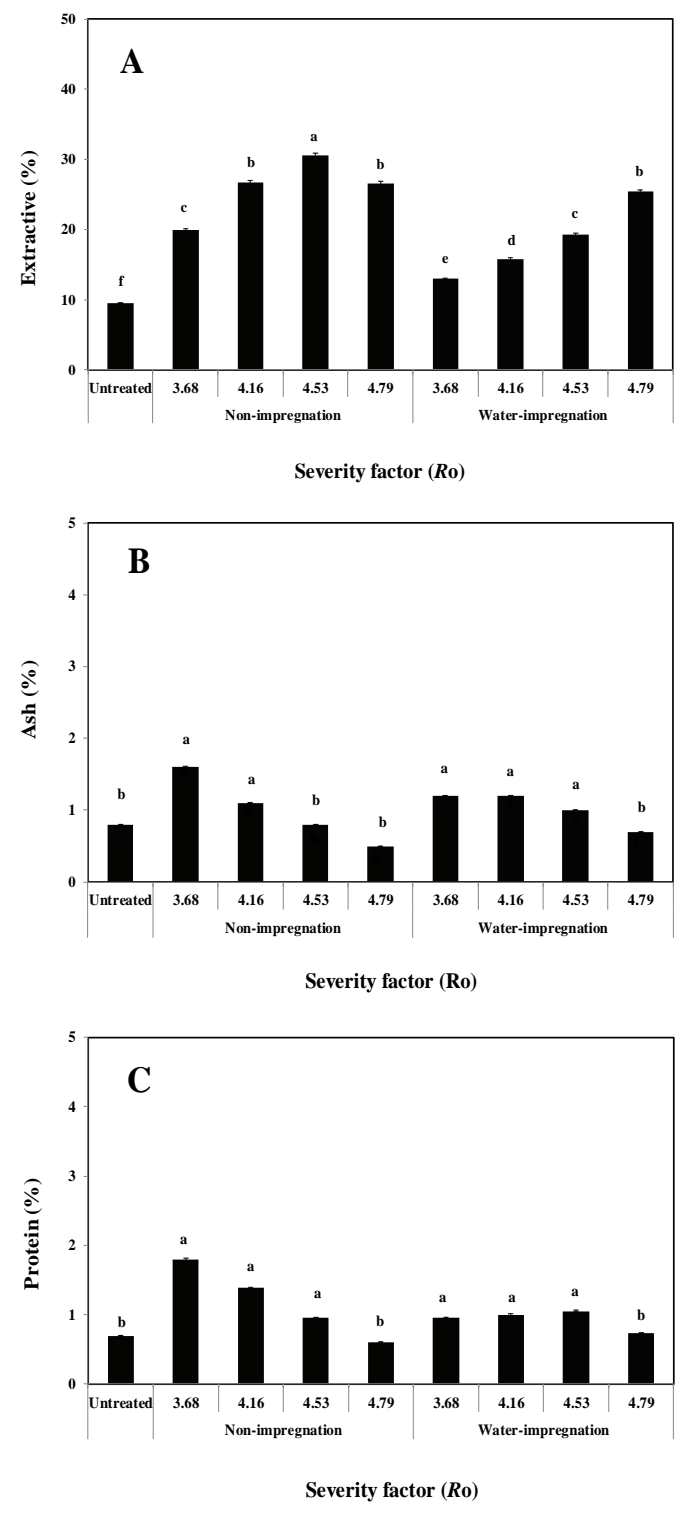

Fig. 4. Effects of impregnation and steam explosion condition on extractive (A), ash (B) and protein (C) content of $P$. densiflora.

extracted with ethanol exhibited extractive contents of $19.9 \%$ and $30.6 \%$, respectively. However, the extractive content in steam-exploded $P$. densiflora decreased when $R o$ was 4.79. The difference is in the composition, since some new compounds form as extractable material, 
while other compounds volatilize or degrade. This increase in extractable material, followed by a decrease with increasing steam explosion temperature, was observed in different wood species. Pierre et al. (2011) also concluded that the extractive content tended to increase up to $250{ }^{\circ} \mathrm{C}$, whereas they decreased at higher temperatures.

The ash and protein contents (Fig. 4B and Fig. 4C) varied within the range of $2 \%$ in water-impregnated/steamexploded $P$. densiflora and decreased when Ro was 4.79. The ash and protein contents in non-impregnated/ steam-exploded $P$. densiflora decreased when $R$ o was 4.53 and 4.79, respectively.

\subsection{Mass balance}

The steam explosion treatment results from the nonimpregnated and water-impregnated samples were compared. Mass balance of non-impregnated/steamexploded and water-impregnated/steam-exploded $P$. densiflora is shown in Fig. 5. When not impregnated with water, solid recovery at $R$ o values ranging from 3.68 to 4.79 from steam-exploded P. densiflora ranged between 70 and $98 \mathrm{~g}$. Solid recovery from waterimpregnated $P$. densiflora samples that were steamexploded at $R$ o values ranging from 3.68 to 4.79 ranged between 81 and $98 \mathrm{~g}$. Solids recovered from waterimpregnated/steam-exploded $P$. densiflora was higher

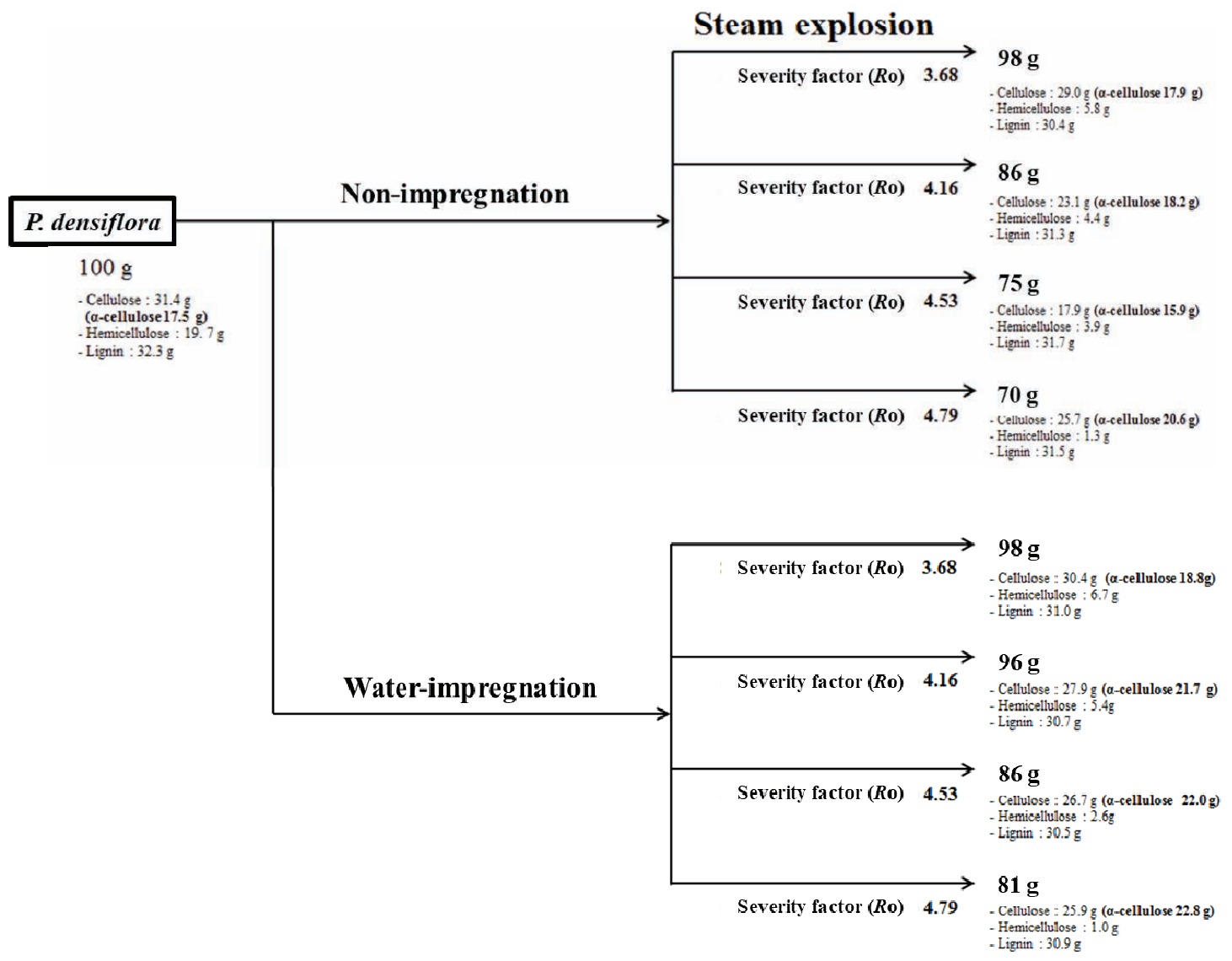

Fig. 5. Mass balance of impregnation (non or water) and steam explosion condition 
than that in the non-impregnated/steam-exploded $P$. densiflora. Also, the cellulose and hemicellulose contents in the water-impregnated/steam-exploded $P$. densiflora were higher than those in the non-impregnated/ steam-exploded $P$. densiflora. In particular, the $\alpha-$ cellulose content in the water-impregnated/steamexploded $P$. densiflora was higher than that in the non-impregnated/steam-exploded $P$. densiflora.

$P$. densiflora that was steam-exploded from the initial biomass when Ro was 3.68 exhibited a recovery yield and overall production of holocellulose (cellulose and hemicellulose) of $68.1 \%$ and $34.8 \mathrm{~g}$, respectively, for the non-impregnated sample. Recovery yield and overall production of holocellulose from the water-impregnated P. densiflora samples were $72.6 \%$ and $37.1 \mathrm{~g}$, respectively.

After water impregnation, the amount of residual holocellulose was $5 \%$ higher than that from the steam-exploded biomass without water impregnation. Thus, the holocellulose yield from the water-impregnated/ steam-exploded $P$. densiflora was higher than the yield from the non-impregnated $P$. densiflora.

\section{CONCLUSION}

Steam explosion is effective in fractionation of lignocellulosic biomass for producing biorefinery fuel. Although significant advances in fractionation of hardwood have been made, progress on that of softwood has been proven difficult. Nevertheless, a combination of water impregnation and steam explosion is considered to be more efficient to this end as it increases holocellulose yield. Steam explosion with water impregnation provides high holocellulose yield from softwood species with higher efficiency than that from the non-impregnated $P$. densiflora. This result suggests a potential process for producing biorefinery fuel from softwood biomass by combining water impregnation and steam explosion.

\section{ACKNOWLEDGMENT}

This study was carried out with the support of 'R\&D Program for Forest Science Technology (Project No. 2013070D10-1819-AA03)' provided by Korea Forest Service (Korea Forestry Promotion Institute).

\section{REFERENCES}

Avellar, B.K., Glasser, W.G. 1998. Steam-assisted biomass fractionation I: process considerations and economic evaluation. Biomass and Bioenergy 14(3): 205-218.

Ballesteros, I., Oliva, J.M., Navarro, A.A., Gonzalez, A., Carrasco, J., Ballesteros, M. 2000. Effect of chip size on steam explosion pretreatment of softwood. Applied Biochemistry and Biotechnology 84: 97-110.

Boussaid, A., Robinson, J., Cai, Y.J., Gregg, D.J., Saddler, J.R. 1999. Fermentability of the hemicellulose-derived sugars from steam-exploded softwood (Douglas fir). Biotechnology and Bioengineering 64: 284-289.

Brownell, H.H., Yu, E.K.C., Saddler, J.N. 1986. Steam explosion pretreatment of wood: effect of chip size, acid, moisture content, and pressure drop. Biotechnology and Bioengineering 28: 792-801.

Cetera, P., Russo, D., Milella, L., Todaro, L. 2019. Thermo-treatment affects Quercus cerris L. wood properties and the antioxidant activity and chemical composition of its by-product extracts. Industrial Crops and Products 130: 380-388.

Clark, T.A., Mackie, K.L. 1987. Steam explosion of the Pinus radiata with sulphur dioxide addition. I. Process optimisation. Journal of Wood Chemistry and Technology 7: 373-403.

Dirckx, O., Triboulottrouy, M.C., Merlin, A., Deglise, X. 1992. Wood photodiscoloration of Abies-Grandis under solar light exposure. Annals of Forest 
Science 49: 425-447.

Ewanick, S., Bura, R. 2011. The effect of biomass moisture content on bioethanol yields from steam pretreated switchgrass and sugarcane bagasse. Bioresource Technology 102: 2651-2658.

Excoffier, G., Toussaint, B., Vignon, M.R. 1991. Saccharification of steam-exploded poplar wood. Biotechnology and Bioengineering 38: 1308-1317. Galbe, M., Zacchi, G.A. 2002. review of the production of ethanol from softwood. Applied Microbiology and Biotechnology 59: 618-628.

Galbe, M., Zacchi, G. 2007. Pretreatment of lignocellulosic materials for efficient bioethanol production. Biofuels 108: 41-65.

Jacquet, N., Vanderghem, C., Danthine, S., Quiévy, N., Blecker, C., Devaux, J., Paquot, M. 2012. Influence of steam explosion on physicochemical properties and hydrolysis rate of pure cellulose fibers. Bioresource Technology 121: 221-227.

Jung, J.Y., Jo, J.S., Kim, Y.W., Yoon, B.T., Kim, C.G., Yang, J.K. 2013. Optimization of Bio-based Succinic Acid Production from Hardwood Using the Two Stage pretreatments. Journal of the Korean Wood Science and Technology 40(2): 111-122.

Jung, J.Y., Yang, J.K. 2016. Enhancing Enzymatic Digestibility of Miscanthus sinensis using Steam Explosion Coupled with Chemicals. Journal of the Korean Wood Science and Technology 44(2): 218-230.

Jung, J.Y., Yang, J.K., Lee, W.H. 2017a. Antioxidant and Safety Test of Natural Extract of Quercus mongolica. Journal of The Korean Wood Science and Technology 45(1): 116-125.

Jung, J.Y., Ha, S.Y., Yang, J.K. 2017b. Response surface optimization of phenolic compounds extraction from steam exploded oak wood (Quercus mongolica). Journal of the Korean Wood Science and Technology 45(6): 809-827.

Jung, J.Y., Ha, S.Y., Park, J.H., Yang, J.K. 2017c.
Optimization of Alkali Pretreatment from Steam Exploded Barley Husk to Enhance Glucose Fraction Using Response Surface Methodology. Journal of the Korean Wood Science and Technology 45(2): 182-194.

Jung, J.Y., Yang, J.K. 2018. A Two-stage Process for Increasing the Yield of Prebiotic-rich Extract from Pinus densiflora. Journal of the Korean Wood Science and Technology 46(4): 380-392.

Kling, S.H., Carvalho, N.C., Ferrara, M.A., Torres, J.C.R., Magalhaes, D.B., Ryu, D.D.Y. 1987. Enhancement of enzymatic hydrolysis of sugarcane bagasse by steam explosion pre-treatment. Biotechnology and Bioengineering 29: 1035-1039.

Kim, J.S., Lee, Y.Y., Kim, T.H. 2016. A review on alkaline pretreatment technology for bioconversion of lignocellulosic biomass. Bioresource Technology 199: 42-48.

Korea Forest Service. 2008. Statistical yearbook of forestry. Korea Forest Service, Seoul.

Lee, J.W., Jeffries, T.W. 2011. Efficiencies of acid catalysts in the hydrolysis of lignocellulosic biomass over a range of combined severity factors. Bioresource Technology 102: 5884-5890.

Liu, C., Wyman, C.E. 2003. The effect of flow rate of compressed hot water on xylan, lignin and total mass removal from corn stover. Industrial and Engineering Chemistry Research 42: 5409-5416.

Mamers, H., Menz, D.N.J. 1984. Explosion pretreatment of Pinus radiata woodchips for the production of fermentation substrates. The Australasian Pulp and Paper Technical Association 37: 644-649.

Maurya, D.P., Singla, A., Negi, S. 2015. An overview of key pretreatment processes for biological conversion of lignocellulosic biomass to bioethanol. 3 Biotech 5(5): 597-609.

Mazet, J.F. 1988. Couleur et qualité des placages de chene et étude de leur comportement photo- 
chimique. Thesis in Wood Science, Nancy I University.

Monavari, S., Galbe, M., Zacchi, G. 2009. Impact of impregnation time and chip size on sugar yield in pretreatment of softwood for ethanol production. Bioresource Technology 100: 6312-6316.

Obernberger, I., Thek, G. 2010. The pellet handbook - The production and thermal utilization of biomass pellets. Earthscan Ltd, London, UK, pp. 549.

Overend, R.P., Chornet, E. 1987. Fractionation of Lignocellulosics by steam-aqueous pretreatments. Philosophical Transactions of the Royal Society of London 321: 523-536.

Pierre, F., Almeida, G., Brito, J.O., Perré, P. 2011. Influence of torrefaction on some chemical and energy properties of maritime pine and pedunculate oak. BioResources 6(2): 1204-1218.

Ramos, L.P., Breuil, C., Saddler. J.N. 1992. Comparison of steam pretreatment of eucalyptus, aspen, and spruce wood chips and their enzymatic hydrolysis. Applied Biochemistry and Biotechnology 34(35): 37-48.

Ropars, M., Marchal, R., Pourquié, J., Vandecasteele, J.P. 1992. Large-scale enzymic hydrolysis of agricultural lignocellulosic biomass Part 1: pretreatment procedures. Bioresource Technology 42:197-204.

Schwald, W., Smaridge, T., Chan, M., Breuil, C.,
Saddler, J.N. 1989. The influence of $\mathrm{SO}_{2}$ impregnation and fractionation on product recovery and enzymic hydrolysis of steam-treated spruce wood. Enzyme Systems for Lignocellulosic Degradation, Elsevier, Finland, pp. 231-242.

Shoulaifar, T.K., DeMartini, N., Willfor, S., Pranovich, A., Smeds, A.I., Virtanen, T.A.P., Maunu, S.L., Verhoeff, F., Kiel, J.H.A., Hupa, M. 2014. Impact of torrefaction on the chemical structure of birch wood. Energy Fuels 28: 3863-3872.

Son, Y., Lee, Y.Y., Lee, C.Y., Yi, M.J. 2007. Nitrogen fixation, soil nitrogen availability, and biomass in pure and mixed plantations of alder and pine in central Korea. Journal of Plant Nutrition 30: 1841-1853.

Sørensen, A., Teller, P. J., Hilstrøm, T., Ahring, B.K. 2008. Hydrolysis of Miscanthus for bioethanol production using dilute acid presoaking combined with wet explosion pretreatment and enzymatic treatment. Bioresource Technology 99(14): 66026607.

Tenrud, I.E., Theander, O., Torneport, L., Vallander, L. 1989. Changes in chemical composition of steam exploded wheat straw during enzymic hydrolysis. Enzyme and Microbial Technology 11: 500-506. Wayman, M., Tallevi, A., Winsborrow, B. 1984. Hydrolysis of biomass by sulphur dioxide. Biomass 6: 183-191. 